\title{
Mensagem do Presidente Emílio Garrastazu Médici ao Congresso Nacional
}

\section{INTRODUÇÃO}

Senhores membros do Congresso Nacional. Não mais se contestam os êxitos logrados, em sua obra renovadora, pelo processo revolucionário em marcha, faz hoje exatamente seis anos. A continuidade dêsse processo não é, pois, algo em que meramente se consinta, porém algo que a opinião comum na realidade deseja. Pela conquista, assim efetuada, dos espíritos, a idéia de direito, que inspirou a decisão política de 31 de março de 1964, estabeleceu em terreno sólido os fundamentos de sua positividade.

Ganhou a consciência popular a noção de que o regime em vigor, pleno de vitalidade e dinamismo, quer plasmar ordem jurídica e social que, sem repudiar totalmente as categorias tradicionais, se ajuste às exigências de uma sociedade que, como a nossa, vive sob o signo da mudança. Sòmente por êsse meio será possível fortalecer e consolidar, em nosso País, a coes̃ão social, de que êle necessita para resolver com tranqüilidade e segurança os problemas do presente e as dificuldades do futuro.

Se não se repudia, de modo total, como instrumento de promoção da coesão social a democracia política ou clássica, não pode esta, contudo, ser mantida para aquêle objetivo, segundo o seu antigo e tradicional estilo. Não sendo fim em si mesma, senão simples processo ou caminho mediante o qual se procura realizar determinado fim, a democracia é fórmula que tem de evoluir, acompanhando a evolução social.

Esquema democrático modelado com o propósito de tutelar direitos individuais não poderia, assim, ser convenientemente utilizado, sem modificações, para pro- teger os direitos sociais. Isto porque, como é corrente, o direito individual se resolve em faculdade cuja realização se deixa ao próprio indivíduo, ao passo que o direito social nasce precisamente do reconhecimento de que o indivíduo só, por suas próprias fôrças, não pode alcançar aquilo a que se acha intitulado por sua condição de homem, necessitando para isso, ao contrário, o concurso governamental.

O direito social, em vez de atingível mediante abstenção do poder público, cria para êste o dever de intervir em quase todos os domínios, de modo a satisfazer às pretensões de bem-estar coletivo que lhe são formuladas. A expansão das funções do Estado, imposta pela necessidade de assegurar os postulados da justiça social, faz parte, dêsse modo, da filosofia política de todos os países, cujas instituições, em razão disso, se transformam inevitàvelmente, ou pela violência ou pelo trabalho pacífico de revolução silenciosa.

O intervencionismo estatal não se caracteriza, entretanto, únicamente pela distensão, cada vez maior, do seu campo de incidência, mas ainda pela forma segundo a qual a ação do poder público se desenvolve. A complexidade crescente da vida moderna obriga, realmente, a que se abra espaço sempre mais largo à competência discricionária da administração, a fim de se assegurar aos mecanismos estatais mais agilidade de movimentos e maior eficiência no desempenho de suas tarefas. A liberdade que a administração adquire, pelo acréscimo do seu poder discricionário, reflete-se, contudo, na liberdade individual, cujos limites, ao menos, se tornam imprecisos, quando envolvidos na zona cinzenta de juízos informados pela conveniência administrativa. 
Cumprindo conciliar, no entanto, os direitos individuais com os denominados direitos de poder, cumpre, também, que o nôvo centro de gravidade da nossa ordem politica assente em modêlo democrático que, superando os padrões da democracia clássica ou liberal, garanta ao homem os seus novos direitos, sem prejuízo dos valôres sob cujo apêlo se formou, dentro dos horizontes do mundo ocidental, a cultura brasileira.

A elegância das fórmulas pelas quais se procura, em nossos dias, resolver êsse difícil problema deve juntar-se, porém, como elemento imprescindível para que se introduza na sociedade nôvo estilo democrático, a integração de todos no esfôrço do Govêrno para a realização dos objetivos sociais. Imperioso é que, fazendo causa comum com a autoridade pública, as fôrças vivas da nacionalidade tragam, sem outro interêsse que o bem comum, a sua contribuição para que se elaborem adequadamente e se executem com eficiência os programas e diretrizes governamentais destinados a promover e sustentar a prosperidade do País e a dar a cada um aquilo que, como pessoa, tem o direito de esperar e exigir.

A êsse esfôrço não faltará, por certo, em grau eminente, aquêle que, pelo seu nobre ofício, o Congresso Nacional possui juntamente o direito e o dever de prestar, como representante direto do povo. A par da contribuição que, no exercício de sua competência, dará, com discernimento e prudência, à tarefa legiferante do terceiro Govêrno da Revolução, o Poder Legislativo desempenhará, certamente, com patriotismo e espírito público, as suas demais e relevantes funções. Entre estas, consoante lugar comum da teoria política, não é de importância somenos a função pedagógica ou educativa, que o grande colégio político, formado pelo Congresso Nacional, pode e deve exercer com maior eficácia, mediante a prática efetiva e real das virtudes cívicas, que se requerem dos condutores de homens.

Disposto a cumprir, até o limite das minhas fôrças, os deveres do meu cargo, estou firmemente persuadido de que poderei contar, para o êxito da missão histórica que, nesta quadra da vida nacional, o Govêrno da República tem o indeclinável encargo de realizar, com a plena e eficiente colaboração dos senhores membros do Congresso Nacional.

Pensando dessa maneira é que tenho a honra de encaminhar a Vossas Exce- lências esta mensagem, mediante a qual dou cumprimento ao art. 81, item XXI, da Constituição Federal.

Brasília, 31 de março de 1970. - Emílio Garrastazu Médici.

\section{CONSIDERAÇõES PRELIMINARES}

A preservação das conquistas básicas dos dois primeiros Governos da Revolução e a implantação de um processo permanente de planejamento governamental exprimem e marcam a continuidade revolucionária.

Dentro dessa filosofia de continuidade e aperfeiçoamento, o terceiro Govêrno da Revolução não procederá, de imediato, à elaboração de nôvo plano global, permanecendo em vigor os programas e projetos já aprovados, naquilo que não fôr modificado pelas Metas e Bases para a Ação do Govêrno, a serem pròximamente anunciadas.

Entre as funções principais do documento, que não constituirá nôvo plano, inclui-se a de definir o conjunto das ações governamentais, notadamente na área das grandes prioridades, a fim de não haver descompasso entre a formulação de projetos e a sua implementação. Evitar-se-á, assim, a dispersão de esforços em novos projetos, antes da conclusão de outros que estejam em marcha, principalmente quando aquêles não revelem prioridade em relação a êstes.

O Govêrno encaminhará ao Congresso Nacional o nôvo Orçamento Plurianual de Investimentos, a ter vigência no triênio 1971/1973 e passivel de revisão anual, até para acréscimo de mais um ano em substituição ao exercício executado, a fim de manter sempre um horizonte de três anos para a programação das despesas de capital. Deverá, outrossim, ser encaminhado ao Congresso, em 1971, o I Plano de Desenvolvimento Econômico e Social, para vigência no período de 1972 a 1974.

A estratégia do Govêrno para o quadriênio $1970 / 1973$ prevê taxa minima de crescimento do Produto Interno Bruto entre 7 e $9 \%$, com a arientação de conduzir a economia brasileira para uma expansão dinâmica da ordem de $10 \%$ ao ano, desde que assegurado o caráter autosustentável do processo. Isso colocaria o Brasil entre os países que mais crescem, atualmente, no mundo desenvolvido e subdesenvolvido. 
A fim de que o País obtenha maiores vantagens do crescimento previsto, pretende-se manter o esfôrço sistemático da redução progressiva da inflação, de forma a possibilitar a relativa estabilidade de preços, com taxas de inflação, no máximo, de $10 \%$ ao ano, a ser atingida ainda no atual Govêrno.

Para alcançar o crescimento previsto, estima-se um investimento bruto fixo anual cuja taxa, em relação ao Produto Interno Bruto, se eleve ao nível de 18 a $20 \%$, ou seja, volume anual de investimentos entre NCr\$ 36 bilhões e NCr\$ 43 bilhões (a preços de 1970), associado a substancial incremento de progresso tecnológico nos métodos e processos de produção, especialmente no que concerne à agricultura.

Êsse nível de investimentos permitirá que a taxa de expansão do emprêgo se eleve de $2,8 \%$ verificado ùltimamente, a $3,5 \%$, em 1973 , contribuindo para reduzir o desemprêgo estrutural existente em segmentos das atividades urbanas e rural e dando oportunidade de colocacão a tôda mão-de-obra adicional que se deverá incorporar ao mercado de trabalho.

Não abdicará, porém, o Govêrno da sua atual política de austera contenção de gastos públicos, principalmente os de custeio burocrático-administrativo. Evitar-se-á a elevação de impostos e a criacão de novios ônus para o setor privado dentro do propósito de dar a êste condições de expansão satisfatórias.

\section{FAZENDA}

Os resultados obtidos em 1969 no campo econômico e financeiro foram bastante satisfatórios, principalmente no que se refere aos objetivos de crescimento do produto $(9 \%$, segundo a estimativa da Fundação Getúlio Vargas) e ao aumento das reservas (561 milhões de dólares), havendo sido largamente superadas as previsões.

A estimativa do crescimento do Produto Interno Bruto, da ordem de $9 \%$, feita pela Fundação Getúlio Vargas, baseia-se no crescimento do produto agrícola em tôrno a $7 \%$ e na variação da produção industrial em níveis superiores a $10 \%$. Isto representa sensivel aceleração em nosso processo de desenvolvimento, pois a taxa média dos últimos 20 anos, a êsse respeito, se situa em tôrno de $6 \%$ e, em 1968 , atingiu-se a $8,4 \%$.

As emissões de capital das sociedades anônimas elevaram-se de $83 \%$, sendo que as subscrições em dinheiro cresceram $30 \%$. As importações de equipamentos, que representam investimentos, aumentaram de $16 \%$. A produção industrial expandiu-se satisfatòriamente em todos os setores, sendo de assinalar que a de automóveis cresceu em $47 \%$. A produção dos principais insumos industriais acompanhou essa evolução, tendo a de aços em lingote aumentado, aproximadamente, de $11 \%$ e o consumo industrial de energia elétrica, de $12 \%$. No setor agrícola, apesar da adversidade das condiçôes climáticas, a produção apresentou crescimento de $7 \%$, em decorrência da elevacão das safras de café (mais $38 \%$ ), soja (mais $46 \%$ ), trigo (mais $36 \%$ ), cacau (mais $15 \%$ ) e algodão (mais $8 \%$ ).

No combate ao processo inflacionário, os resultados, mesmo não havendo sido inteiramente satisfatórios, revelam sensível avanço em relação ao ano anterior. Os indicadores mais gerais evidenciam uma diminuição nas variações de preços de 1969 da ordem de $20 \%$ em relação a 1968.

As exportações brasileiras aceleraram o seu ritmo de expansão, tendo crescido $14 \%$ em 1968 e $20 \%$ em 1969, graças a uma política dinâmica de estímulos. A exportação de manufaturados apresentou aumento acima da média; os minérios mantiveram o seu acentuado crescimento; e, entre os produtos agrícolas, evidenciou-se a exportação de algodão. O café apresentou pequena elevação. As importações, após o crescimento de $20 \%$ que se verificou no ano anterior, expandiram-se menos acentuadamente, havendo crescido, no global, em $6 \%$. A variação de sua composicão foi positiva, porém, tendo-se registrado maior crescimento na importação de equipamentos e manufaturas, com sensivel redução na de gêneros alimentícios e bebidas. Com êsse comportamento do comércio externo, no qual as exportações atingiram US\$ 2 bilhões e 260 milhões e as importações alcançaram US\$ 1 bilhão e 960 milhôes (FOB), a balança comercial apresentou um saldo de US\$ 300 milhões. Considerados os serviços e as movimentações de capital, a balança de pagamentos revelou superavit da ordem de US\$ 561 milhões, elevando, assim, substancialmente, as nossas reservas de divisas.

Foi possível apresentar um crescimento de, aproximadamente, $36 \%$ da receita arrecadada, o qual se revelou mais acentuado nos impostos diretos. A despesa sofreu uma elevação de apenas $28 \%$ e, ha- 
vendo sido menor que o aumento do Produto Interno Bruto, daí resultou que a participação dos gastos do Govêrno Federal, como percentagem do produto, declinou entre 1968 e 1969. Obteve-se isso, mesmo com a redução do montante de diferimentos previstos para o exercício e o atendimento, mediante créditos adicionais, de algumas despesas de caráter prioritário. Com tal comportamento da Receita e da Despesa, o deficit previsto em NCr\$ 1 bilhão e 200 milhões foi reduzido para 756 milhões, o que representa apreciável avanço na política de combate à inflação.

Os meios de pagamento expandiram-se em $30,6 \%$, tendo-se verificado um aumento líquido de NCr\$ 1 bilhão e 300 milhões no meio circulante. Os empréstimos bancários no setor privado aumentaram de $42 \%$, sendo $53,6 \%$ no Banco do Brasil S.A. e $36,6 \%$ nos demais estabelecimentos. Os crescimentos dos depósitos do público foram mais moderados: $34,6 \%$ no Banco do Brasil S.A. e 25,7\% nos demais. A maior expansão das aplicações tornou-se possivel em decorrência da entrada de recursos do exterior, principalmente pelos mecanismos da Instrução n. ${ }^{\circ} 289$ e da Resolução n.o 63 , além de maior assistência do Banco Central.

A manutenção de paridade realista do cruzeiro em relação ao dólar, somada aos incentivos, elevou as exportações ao nível de US\$ 2.260 milhões, proporcionando um saldo de US\$ 300 milhôes na balança comercial (importação FOB), conforme já se indicou. Também os ingressos de capitais financeiros revelaram-se substanciais, atingindo cifras em tôrno de .... US\$ 800 milhões e permitindo que a $\mathrm{ba}$ lança de pagamentos proporcionasse acumulação liquida de divisas de US\$ 561 milhões.

\section{COMUNICAÇÕES}

No campo das comunicações, são êstes os principais objetivos a serem alcancados em 1970; rever e consolidar a legislação de telecomunicações, especialmente a resultante de decisões e resoluções do CONTEL; estimular as iniciativas que visem à formação de pessoal capacitado, em todos os níveis, para a operação do setor; assegurar continuidade e flexibilidade na obtenção, distribuição e contrôle de recursos necessários para implantar, operar e ampliar o sistema de telecomunicações de interêsse para o País; estabelecer um Centro de Estudos e Pesquisas para as telecomunicações nacionais; pro- piciar todo o apoio à indústria, de modo a garantir a expansão das comunicações em têrmos condizentes com o desenvolvimento nacional; promover a padronização de equipamentos e componentes, bem como de normas de operação e manutenção dos meios de comunicação; prosseguir na implantação do Sistema Básico do Plano Nacional de Telecomunicações.

\section{JUSTIÇA}

No campo da elaboração legislativa, referente à Justiça, árdua tarefa impõese ao Govêrno em 1970. Serão levadas a cabo a preparação de leis complementares à Constituição de codificação e de leis de cumprimento à Constituição. A preparacão de leis complementares à Constituiçã̃o é imperativo inadiável. A Carta Magna prevê a elaboração de tais leis, que devem desdobrá-la em pontos de especial relevância.

Assim, serão elaborados e apresentados projetos de leis complementares sôbre: a) a criação de Estados e Territórios; b) o estabelecimento de requisitos mínimos de população e renda pública, bem como a forma de consulta prévia às populações para a criação de municípios; c) a remuneração de vereadores das capitais e dos municípios de população superior a 200 mil habitantes; d) a instituição de regiões metropolitanas. Estão sendo preparados projetos de Código Civil, de Código de Processo Civil, de Processo Penal, de Navegação, de Contravenções, de Execuções Penais, do Trabalho, de Processo do Trabalho, de Menores, do Direito do Autor, assim como de Lei Geral de Aplicação das Normas Jurídicas.

Os projetos de lei referentes ao cumprimento da Constituição são quatro. O primeiro diz respeito à "representação do Procurador-Geral da República por inconstitucionalidade de lei ou ato normativo federal ou estadual. O segundo refere-se à anulação de atos Administrativos de natureza tributária, conforme está previsto no art. 122 da Constituição. O terceiro relaciona-se com a interpretação do art. $144, \S 5 .^{\circ}$, da Constituição, que confere ao Tribunal de Justiça competência para dispor sôbre a divisão e a organização judiciárias do Estado. E o quarto diz respeito à situação jurídica das pessoas naturais de nacionalidade portuguêsa, as quais, segundo o art. 199 da Constituição, não sofrerão qualquer restrição em virtude da condição de nascimento se admitida a reciprocidade em favor de brasileiros". 


\section{AGRICULTURA}

O aumento da produtividade, a circulação eficiente das riquezas, o abastecimento do mercado interno e o fomento das exportacốes correspondem à filosofia global do Govêrno no setor da agricultura.

Procurando sensibilizar o público e motivar a iniciativa privada, de modo a construir uma infra-estrutura que estimule a atividade agropecuária, algumas medidas foram adotadas, entre elas: extensão do crédito rural; redução da carga fiscal sôbre a produção agropecuária; regulamentação do Impôsto de Renda Rural; reformulação da política de abastecimento.

A atuação governamental prosseguirá no cumprimento de outras metas prioritárias nos seguintes setores básicos da producão: abastecimento (construção de centrais nas cidades com mais de 500 mil habitantes); colonização (ocupação imediata dos espacos territoriais vazios); produção de alimentos (aumento das culturas alimentícias e melhoria dos sistemas de armazenagem e de escoamento dos produtos); irrigação e drenagem (especialmente no Nordeste e no Vale do São Francisco); exportação (programa de expansão das vendas externas de produtos primários); projetos regionais e locais (em convênios com os Estados, para o estabelecimento de cinturōes verdes).

\section{SAƯDE}

Com referência a assuntos de saúde, as características das regiões mais pobres do País são a elevada taxa de crescimento; alta natalidade; a predominância de jovens na população; a grande concentração populacional nos centros urbanos. As infecções, parasitoses, subnutrição e condiç̃es desfavoráveis de vida são responsáveis pelas doenças, principalmente em certas localidades do Nordeste.

Impõe-se melhorar ao máximo êsse quadro. As diretrizes básicas de saúde terão, entre outros, os objetivos de combater d o e n c a s transmissíveis; realizar campanhas educativas de higiene; incrementar o saneamento básico, ampliando e melhorando os sistemas de esgotos; executar medidas de proteção à maternidade e à infância; criar e expandir a rêde de unidades locais de saúde; incentivar pesquisas puras e aplicada à saúde, tanto pública como individual; atender aos problemas de assistência médica e hospitalar.
Quanto às doenças transmissíveis, a atividade prioritária será o combate à varíola, malária, febre amarela, doença de Chagas, esquistossomose, adotando-se sempre que possível a vacinação. O saneamento será ampliado e melhorado, já que existe perfeito entrosamento entre os Ministérios da Saúde e do Interior.

A infância terá os benefícios de intensos programas educativos e da integração dos órgãos oficiais, oficiosos e particulares, que funcionarão de forma a evitar o paralelismo de atividades. Para o desenvolvimento técnico, haverá prioridades aos trabalhos de pesquisa, ao preparo de pessoal qualificado e à elaboração de medicamentos para baratear-lhes o custo.

\section{POLITICA EXTERNA}

A política externa brasileira procurará adaptar-se às transformações da vida internacional. Essa flexibilidade identificará, em situações novas, as conveniências do Brasil. Por fôrça da nossa vocação pacífica, entretanto, e de nossos ideais de harmonia e fraternidade, essas conveniências têm coincidido, através dos tempos, com os interêsses globais da humanidade.

A harmonia internacional não se pode fundar na manutenção da atual desigualdade entre os povos; e por desejar preservar os direitos de todos os países à utilização pacífica dos progressos da ciência, o Brasil, favorável ao desarmamento mundial, continuará contrário à assinatura do Tratado de Não Proliferação das Armas Nucleares na sua redação atual.

Exige, por outro lado, que o fundo do mar e o espaço cósmico sejam utilizados como patrimônio de tôda a humanidade. Adotando uma política aberta para com todos os povos, o Brasil dá lugar de relêvo, em sua política internacional, às relações com os países do continente americano.

\section{EDUCAÇão}

Após a análise crítica do sistema educacional, ficaram evidentes sérias deficiências de organização e funcionamento, cuja neutralização deve ser feita com urgência.

A desconexão entre os graus de ensino e a falta de entrosamento entre os currículos dos diversos graus é uma das características mais negativas de nosso ensino. Visando a dinamizar o ensino brasileiro já foram realizados diversos convênios. 
A desconexão entre os diversos graus de ensino; a alarmante evasão do ensino primário e, nêle, a repetência em taxa muito alta; a falta de planificação da oferta; a seletividade antidemocrática, sobretudo do ensino médio; o fenômeno dos excedentes; o despreparo de grande parcela do magistério e sua baixa remuneração; e o elevadíssimo índice de analfabetismo são alguns dos mais graves e prementes problemas que o Govêrno vai enfrentar e solucionar.

O sistema é tão falho que sua inadequação se patenteia dramáticamente nos próprios exames de admissão ao curso secundário e de vestibular ao curso superior. Além disso, currículos irrealísticos exigem forte carga horária de informações acadêmicas, sem qualquer preocupação de qualificação gradativa de mãode-obra nacional ao longo das diversas etapas dos cursos.

Para melhor produtividade do ensino, está pronto o estudo para integração do curso primário com o primeiro ciclo do atual curso médio, de modo a criar-se 0 conceito de educação fundamental, que virá a corrigir os defeitos de desconexão hoje existentes entre os curriculos dêsses graus de ensino.

Em 1971, em todo o território nacional, estará implantada a nova sistemática de ensino fundamental. Neste ensino, os ginásios orientados para o trabalho (pluricurriculares) desempenharão papel de relêvo para despertar vocações. Funcionarão como unidades de ensino que permitirão o contato dos alunos com oficinas de artes e ofícios, não tendo caráter profissionalizante, mas pré-vocacional.

Ao ensino médio ficarão reservados os cinco ramos: colegial, industrial, comercial, agrícola e normal. Todo o esfôrço do Govêrno será no sentido de quebrar o quase monopólio do colegial que atualmente detém $73 \%$ do total de matrículas. Impõe-se também formar maior número de professôres primários para diminuir a percentagem elevada de leigos $(40 \%)$ em exercício. As escolas industriais visarão à formação de técnicos de nível médio de que se ressente o mercado de trabalho nacional.

A oferta de ensino superior será aumentada por meio de ampliação das unidades existentes, além de ser planificada a oferta, levando-se em conta as potencialidades do mercado de trabalho.

O Govêrno atuará através do Plano Nacional de Educação, no ensino médio e superior, nos Estados e municípios, com orçamentos e específicos da educação estadual e municipal, um montante previsto de NCr\$140 milhões criando ainda salário fixo profissional para o magistério. Isto implicará no incremento da taxa de escolarização para $80 \%$. Haverá ainda assistência total ao aluno, além de distribuição de bôlsas de estudo. Para isso, está em estudo um plano de seguroeducação para possivel adoção ainda êste ano com o objetivo de garantir o estudante contra o infortúnio.

\section{INTERIOR}

A efetiva descentralização dos serviços, mediante o fortalecimento das estruturas locais, constitui um dos objetivos principais do Govêrno na sua política relativa ao interior. E essa atuaçẫo cada vez mais se desenvolve em sintonia entre a esfera federal e os Governos ao diagnóstico e à formulação de soluções prioritárias, à formação e aperfeiçoamento de pessoal, ao acompanhamento da execução de projetos e atividades e à instituição de um sistema de informações para o planejamento.

Consolidar a ocupação da Amazônia é um dos itens principais e essa consolidação representa outro objetivo fundamental do Govêrno, possibilitando, destarte, a crescente integração daquela vasta área às demais regiões do País.

Dois aspectos estratégicos no programa de consolidação da ocupação da Amazônia merecem destaque especial: a instalação de campus avançado de universidades em várias cidades da região, como conseqüência dos trabalhos do Projeto Rondon, e o contínuo aperfeiçoamento de métodos e sistemas, desde o planejamento até a execução, na administração dos territórios federais.

Prossegue, da mesma forma, a política de desenvolvimento para 0 Nordeste. Para aquela área estão previstos diversos planos nos vários setores da economia popular, com particular atenção para o fortalecimento e aumento da produtividade da agricultura, atingindo as etapas de planejamento, pesquisa e a introdução de novas técnicas.

Destaca-se nesse capítulo a atenção do Govêrno com relação à saúde pública, através do programa denominado Década do Saneamento Básico, ao término da qual devem estar atendidos com serviços regulares de abastecimento d'água, pelo menos $80 \%$ dos habitantes urbanos do País. 


\section{TRABALHO E PREVIDENCIA}

O Govêrno não pretende acenar com promessas que não possa cumprir e realizar. A manutenção da política salarial adotada pelos últimos Governos ainda obriga os assalariados a uma cota de sacrifício, mas isso tem sido compensado por modalidades de salário indireto ou suplementar, a que se procura dar maior ênfase e amplitude.

A substituição do regime de correção monetária pelo de equivalência salarial nos planos do BNH, as melhorias introduzidas no INPS e o programa, já iniciado, de reforma da Justiça do Trabalho são fatôres influentes na obtenção da harmonia social.

Não se limita, porém, o Govêrno, aos aspectos conjunturais do problema das relações de trabalho. A sua constante preocupação é a de cumprir a lei e assegurar aos trabalhadores os direitos que visem à melhoria de sua condição social. O Govêrno não compreende a prática da justiça social senão em têrmos de distribuição equânime dá riqueza global.

O atual Govêrno já encontrou, quando assumiu, a área sindical tranquilia e em ordem, como ainda hoje se apresenta, com clara possibilidade de entendimento fecundo entre o Govêrno, trabalhadores e empresários. O diálogo, dentro dêsse clima e graças a êle, tem sido o mais franco e realista possivel, mas a ação fiscalizadora e repressiva do Govêrno não poderá, sem dúvida, se deixar de fazer sentir sempre que se registrar, quer de parte dos empregadores, quer de parte dos empregados, infração às normas aqui definidas e que se consubstanciam nos preceitos da Constituição e das leis específicas. A obediência aos cânones legais não impedirá, entretanto, o surto do sindicato livre, que se deseja em primeiro lugar, livre das influências ideológicas e das injunções político-partidárias.

\section{FORCAS ARMADAS}

As Fôrças Armadas, ante a iminência de uma crise decorrente do impedimento do Presidente Arthur da Costa e Silva, tiveram de arcar com a responsabilidade de conduzir, temporàriamente, os destinos da Nação. Naquela difícil conjuntura, ao assegurar a paz e a ordem, mesmo enfrentando episódio de delicada repercussão internacional, permitiram o prosseguimento da obra do desenvolvimento nacional e lograram uma solução de continuidade revolucionária, que realçou a unidade existente entre aquelas Fôrças e patenteou a inequívoca confiança que desfrutam perante o povo brasileiro.

No âmbito de suas atividades profissionais, as três Armas continuam a executar regularmente a reforma administrativa que permitirá um aumento de produtividade; paralelamente, continuam a prestar sua colaboração ao desenvolvimento econômico do País, mediante a participação nos programas governamentais de educação, transportes, assistência e previdência.

\section{INDUSTRIA E COMÉRCIO}

Integração do parque industrial e aumento da produtividade de seus setores tradicionais têm sido os objetivos básicos da política de desenvolvimento industrial do Govêrno, que relata:

- Em 1969, a produção industrial cresceu em 10,9\%, taxa bastante expressiva, sobretudo se comparada com os índices da indústria brasileira nos dois últimos decênios e com as taxas de expansão da indústria internacional.

A atuação do Govêrno nesse domínio determinou substancial aumento no valor dos projetos aprovados, que atingiram NCr\$ 4 bilhões e 259 milhões em 1969, contra NCr\$ 1 bilhão e 143 milhões em 1968.

E destacada a atuação dos órgãos competentes da administração que, orientando os investimentos no setor químico e petroquímico, permitirá, já no corrente ano, o início da produção, no País, de elementos básicos para a expansão no setor, como o etileno, benzeno, polietileno, ácido nítrico, ácido sulfúrico, fertilizantes complexos, dióxido de titânio e outras.

A meta a ser atingida nos próximos anos pela siderurgia é a completa autosuficiência e, no domínio das exportações, os esforços são canalizados no sentido de se manter a mesma excepcional taxa de crescimento dos últimos anos, de modo a ajustar o setor externo da economia ao nosso crescimento.

Como nos demais setores da indústria e do comércio, o Govêrno revela otimismo em relação aos principais produtos agrícolas de exportação. No ano passado exportamos 19 milhốes e 600 mil sacas de café e as estimativas da produção nacional de açúcar para êste ano são promissoras, devendo atingir 75 milhões de sacas. A produção de 1969 foi de 70 milhões e 300 mil sacas. 


\section{TRANSPORTES}

No setor de transportes, o objetivo fundamental é assegurar a satisfação do conjunto e necessidades da nação pelo menor custo para a economia. Para isso, está sendo implantada uma concepção unificada dos transportes nacionais que obterá uma coordenação racional entre os sistemas federal, estaduais e municipais, bem como entre as diferentes modalidades de transportes existentes.

A ação governamental visará à superação das insuficiências qualitativas e quantitativas da infra-estrutura, à redução dos custos reais dos serviços, à autosuficiência econômica das emprêsas e ao funcionamento integrado e equilibrado do setor.

No setor rodoviário, o Govêrno prosseguirá o programa em curso, visando ao aperfeiçoamento da execução rodoviária e à obrigatoriedade de preparação prévia de estudos de viabilidade de projetos. Quanto às ferrovias, a principal meta será a redução do deficit operacional, numa taxa de 10 a $15 \%$ ao ano.

Os portos sofrerão descentralização administrativa, mediante a criação de sociedades de economia mista que, sob - regime de administração autônoma, serão responsáveis pelas operações portuárias. No setor das vias navegáveis, interiores, continuarão os estudos para - levantamento da rêde fluvial brasileira e do potencial de carga para 0 transporte hidroviário.

\section{MINAS E ENERGIA}

No setor de energia elétrica, os programas iniciados vềm tendo prosseguimento regular, havendo sido recuperados em quase todo o País os atrasos do passado. A nova política de energia elétrica tem, com efeito, possibilitado não só essa ação como também o equilíbrio econômico e financeiro das emprêsas.

Após cuidadosa preparação serão dados, em 1970, os passos iniciais para a construção da primeira central núcleoelétrica de potência, com finalidade comercial. Já se acha determinada sua localização entre Rio e São Paulo, no Município de Angra dos Reis, estando sua potência fixada ao nível de $500 \mathrm{mil} \mathrm{kw}$. Dentro de alguns meses, serão publicados os editais referentes ao fornecimento de equipamentos e instalações para essa obra pioneira.

$\mathrm{Na}$ extração do carvão min̄eral foram alcançados significativos progressos em têrmos de produtividade e no setor enérgético estão sendo acelerados os'trabalhos de pesquisa de petróleo na plataforma continental, já havendo sido contratados novos equipamentos para êsse fim. 